INTERNATIONAL JOURNAL OF SYSTEMATIC BACTERIOLOGY

Vol. 16, No. 3 July 1966 pp. 313-340

\title{
METHODS FOR CHARACTERIZATION OF STREPTOMYCES SPECIES ${ }^{1}$
}

E. B. Shirling and D. Gottlieb

\author{
Department of Botany and Bacteriology \\ Ohio Wesleyan University, Delaware, Ohio \\ and \\ Department of Plant Pathology \\ University of Illinois, Urbana, Illinois
}

ABSTRACT. The methods used by collaborators in the International Streptomyces Project (ISP) for emendation of descriptions of type and neotype strains of the genus Streptomyces (Actinomycetales) are presented.

An international cooperative effort, now in progress, is directed toward collection of type cultures of the Streptomyces species for deposition with the Centraalbureau voor Schimmelcultures (CBS), Baarn. From this center the reference cultures will be supplied to other culture collections so that they are available throughout the world.

An essential adjunct to this activity is the redescription of each type culture in terms of currently acceptable criteria and methods. The urgent need for an authentic reference collection, accompanied by standardized characterizations for each species, has been pointed out by spokesmen for the several meetings and conferences which culminated in this project. (See, for example, Gottlieb, 1959, 1961; Küster, 1959; Krasil'nikov, 1961.) More than 40 investigators ${ }^{2}$ representing 17 countries are participating in this research. Each culture is described independently by three of these cooperating specialists in different laboratories before it is deposited in the reference collection.

1 This project is supported in part by a research grant from the National Science Foundation, U.S. A. The Subcommittee on Actinomycetes of the Committee on Taxonomy, A.S.M. and the Subcommittee on: Taxonomy of Actinomycetes of the International Committee on Bacteriological Nomenclature are co-sponsoring advisors.

2 Participants in the 1964-1965 studies are listed on p. 338 . 
This manual contains the criteria and methods adopted for the project. It reflects the results of two extensive cooperative studies directed toward selection of stable properties and reproducible procedures for characterization of streptomycetes. One study conducted under the direction of the Subcommittee on Actinomycetes of the Committee on Taxonomy, American Society for Microbiology was reported by the Chairman, Dr. D. Gottlieb (196I). A similar preliminary study on an international basis was reported for the Subcommittee on Taxonomy of Actinomycetes of the International Committee on Bacteriological Nomenclature by the Secretary, Dr. E. Küster $(1961,1964)$. The descriptive criteria are essentially the same as those included in the recommendations of this international subcommittee for descriptions of Actinomycetales appearing in patent applications (Gottlieb, 1963). The methods in mimeographed form have been used successfully for the description of type and neotype strains of more than 200 named species submitted to ISP collaborators during 1964 and 1965, and are now in use for a continuation of the project. Only minor editorial changes have been made except that the test for nitrate reduction (including medium 8 , Bacto-nitrate broth) has been omitted. This characteristic proved unstable and has been dropped from the study.

It is hoped that the characterizations used in this manual will be included in future descriptions of Streptomyces species so that direct comparison can be made with descriptions for type cultures in the reference collections.

\section{MATERIALS AND GENERAL METHODS}

\section{CUITURE MEDIA}

Prepare Difco3,o 4 dehydrated culture media as instructed on labels of containers. If the dehydrated media are not used, use formulas and instructions in this manual as a guide to preparation of the media.

\footnotetext{
3 All culture media described in this manual have been prepared especially for the I.S.P. by Difco Laboratories as preformulated dehydrated media. This important contribution by Difco Laboratories is gratefully acknowledged. When Difco dehydrated media are used, instructions on labels supersede instructions in the manual.

4 Difco Laboratories, Detroit, Michigan, U.S. A. 48201
} 
Sterilize culture media in the autoclave at $121^{\circ} \mathrm{C}$. Sterilize loosely packed tubes or flasks containing less than 500 $\mathrm{ml}$ for 15 minutes; sterilize larger quantities for 20 minutes. (Do not autoclave carbon compounds to be used in the carbon utilization tests. Special instructions for sterilizing these compounds are given with medium 9.) Adjust $\mathrm{pH}$ of media with $\mathrm{NaOH}$ or $\mathrm{HCl}$ before addition of agar and before sterilization.

Trace salts solution (Use as directed in media $3,4,5$ and 7 if prepared from formulas. Do not add to the corresponding Difco dehydrated media.)

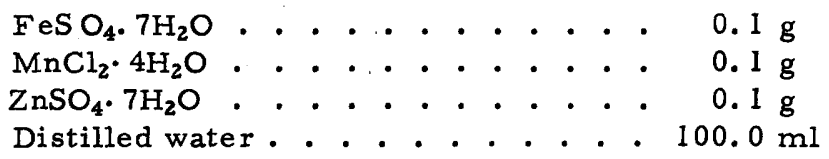

Medium 1: Tryptone-yeast extract broth (Pridham and Gottlieb, 1948)

Bacto-Tryptone (Difco) . . . . . $5.0 \mathrm{~g}$

Bacto-Yeast Extract (Difco) . . . . $3.0 \mathrm{~g}$

Distilled water......... 1.0 liter

pH 7.0 to 7.2 before autoclaving

Dispense $5 \mathrm{ml}$ of broth into test tubes with a diameter of $20 \mathrm{~mm}$ or more. Use these test tubes for initiating growth from lyophile pellet. One tube will be needed for each culture studied.

Dispense $50 \mathrm{ml}$ of the broth into each $250 \mathrm{ml} \mathrm{Erlen-}$ meyer flask (or $25 \mathrm{ml}$ into $125 \mathrm{ml}$ flask). These flasks will be used for preparation of washed inoculum (p. 322). One flask will be needed for each culture studied.

Medium 2: Yeast extract-malt extract agar (Pridham et al., 1956-57)

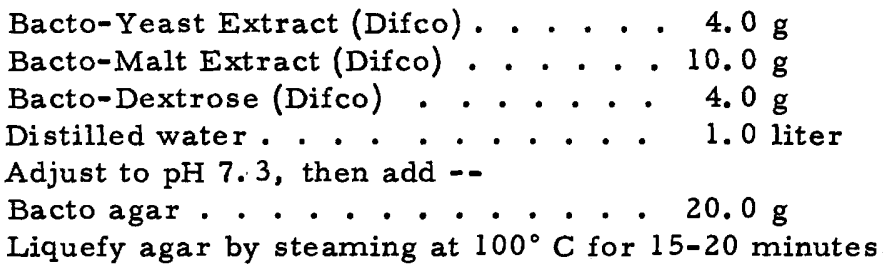


Dispense appropriate amount for a slanting into at least 6 tubes for each culture. Sterilize by autoclaving; cool tubes as slants. Use the agar slants for preparation of stock cultures (page 321).

Also sterilize medium 2 in flasks for pouring the sterilized medium into Petri dishes. Seven standard $90 \mathrm{~mm}$ dishes containing $25 \mathrm{ml}$ per plate will be needed for each culture. (Pages 325 and 330).

Medium 3: Oatmeal agar (Küster, 1959a).

Oatmeal. . . . . . . . . . $20.0 \mathrm{~g}$

Agar. . . . . . . . . $18.0 \mathrm{~g}$

Cook or steam $20 \mathrm{~g}$ oatmeal in $1000 \mathrm{ml}$ distilled water for 20 minutes.

Filter through cheese cloth.

Add distilled water to restore volume of filtrate to $1000 \mathrm{ml}$.

Add trace salts solution (page 315 ). . . $1.0 \mathrm{ml}$

Adjust to $\mathrm{pH} 7.2$ with $\mathrm{NaOH}$.

Add $18 \mathrm{~g}$ agar; liquefy by steaming at $100^{\circ} \mathrm{C}$ for 15-20 minutes. 
Sterlize in flasks for pouring into Petri dishes. Seven standard $90 \mathrm{~mm}$ dishes containing $25 \mathrm{ml}$ per dish will be needed for each culture. (Pages 325 and 330)

Swirl medium before pouring to as sure even distribution of the oatmeal.

\section{Medium 4: Inorganic salts-starch agar (Küster, 1959a.)}

Solution I: Difco soluble starch $10.0 \mathrm{~g}$. Make a paste of the starch with a small amount of cold distilled water and bring to a volume of $500 \mathrm{ml}$.

\section{Solution II:}

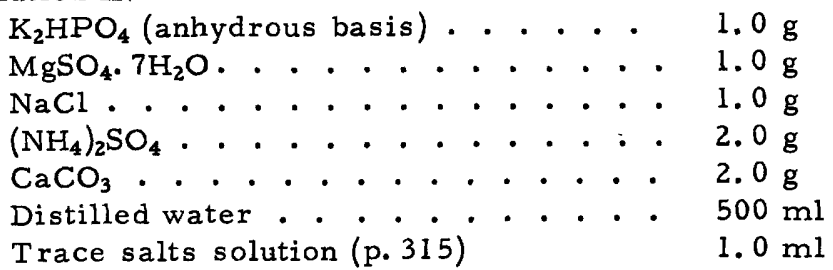

$\mathrm{pH}$ should be between 7.0 and 7.4. Do not adjust

if it is within this range.

Mix starch suspension and salts solution.

Add agar (Difco). . . . . . . . $20.0 \mathrm{~g}$

Liquefy aga $\mathrm{r}$ by steaming at $100^{\circ} \mathrm{C}$ for $15-20$ minutes.

Sterilize in flasks for pouring into Petri dishes. Seven standard $90 \mathrm{~mm}$ dishes containing $25 \mathrm{ml}$ per dish will be needed for each culture. (Pages 325 and 330)

Medium 5: Glycerol-asparagine agar (Pridham and Lyons, 1961)

L-asparagine (anhydrous basis) . . . $1.0 \mathrm{~g}$

Glycerol. . ............ $10.0 \mathrm{~g}$

$\mathrm{K}_{2} \mathrm{HPO}_{4}$ (anhydrous basis) ...... $1.0 \mathrm{~g}$

Distilled water. . . . . . . . . . 1.0 liter

Trace salts solution (page 315). . . . . $1.0 \mathrm{ml}$

The $\mathrm{pH}$ of this solution is about 7.0-7.4. Do not adjust

if it is within this range.

Agar . . . . . . . . . . . $20.0 \mathrm{~g}$

Liquefy agar by steaming at $100^{\circ} \mathrm{C}$ for $15-20$ minutes.

Sterlize in flasks for pouring into Petri dishes.

Seven standard $90 \mathrm{~mm}$ dishes containing $25 \mathrm{ml}$ per dish 
will be needed for each culture. (Pages 325 and 330)

The final $\mathrm{pH}$ of the medium after sterilization with agar and solidification is about 7. 4 .

Medium 6: Peptone-yeast extract iron agar (Tresner and Danga, 1958)

Bacto-Peptone Iron Agar, dehydrated (Difco) $36.0 \mathrm{~g}$ Bacto-Yeast Extract (Difco). . . . . . $1.0 \mathrm{~g}$ Distilled water............. 1.0 liter pH should b 7.0-7.2 before autoclaving; adjust if

necessary.

Liquefy agar by steaming at $100^{\circ} \mathrm{C}$ for $15-20$ minutes.

Dispense appropriate amount for slanting into 2 tubes for each culture. Sterilize and solidify as slants. (Page 334). (Note that less than 1 liter of this medium is easily prepared by using a proportionately smaller amount of the dehydrated peptone iron agar and adding yeast extract in proportion of $0.1 \%$ of water used.)

Bacto-Peptone Iron Agar, dehydrated, contains the following ingredients when reconstituted as $36.58 \mathrm{grams}$ per liter of water: Bacto-Peptone, $15 \mathrm{~g}$; Proteose Peptone, Difco, $5 \mathrm{~g}$; Ferric Ammonium Citrate, $0.5 \mathrm{~g}$; Dipotassium Phosphate, $1 \mathrm{~g}$; Sodium Thiosulfate, $0.08 \mathrm{~g}$ : Bacto-Agar, $15 \mathrm{~g}$.

Medium 7: Tyrosine agar (Shinobu, 1958)

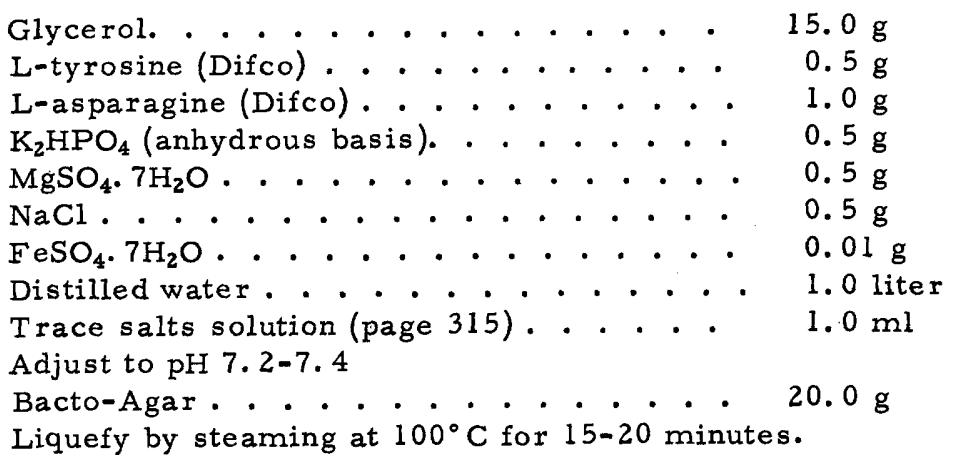

Dispense appropriate amount for slanting into 2 tubes for each culture; sterilize and solidify as slants. (Page 333). 
Medium 8: Nitrate broth (Deleted because of unreliability of the nitrate-reduction test).

Medium 9: Carbon utilization medium (Modified from Pridham and Gottlieb, 1948)

A. Sterile carbon sources

Use chemically pure carbon sources certified to be free of admixture with other carbohydrates or contaminating materials. Carbon sources for this test are:

No carbon source (negative control)

D-glucose (positive control)

L-arabinose

Sucrose

D-fructose

D-xylose

Rhamnose

I-inositol

Raffinose

D-mannitol

Cellulose

Sterilize without heat by one of the following methods:

1. Filtration. Filter sterilize $10 \%$ solution through bacteriological filter. (i-Inositol and cellulose are not sufficiently. soluble for sterilization by this method-use one of the methods described below.)

2. Ether sterilization. Weigh an appropriate amount of the dry carbon source and spread as a shallow layer in a pre-sterilized Erlenmeyer flask fitted with a loose cotton plug. Add sufficient acetone-free ethyl ether $\left(\mathrm{C}_{2} \mathrm{H}_{5}\right)_{2} \mathrm{O}$ to cover the carbohydrate. (OBSERVE PRECAUTIONS AGAINST FIRE ! Allow ether to evaporate at room temperature under a ventilated fume hood overnight or longer. When all ether has evaporated add sterile distilled water aseptically to make a $10 \% \mathrm{w} / \mathrm{v}$ solution of the carbon source.

3. Ethylene oxide sterilization. (Judge and Pelczar, 1955). Make a $10 \% \mathrm{w} / \mathrm{v}$ solution of the carbon source. Cool the liquid in an ice bath to $3-5^{\circ} \mathrm{C}$ and add 1 volume per cent liquid (cold) ethylene oxide with a chilled pipette or syringe. Agitate the solution. Leave it in the cold ice bath under a ventilated fume hood for 
1 hour. Transfer to a warm water bath (about $45^{\circ} \mathrm{C}$ ) UNDER FUME HOOD to permit complete volitilization of the ethylene oxide. The vapors are toxic and explosive.

Carbon sources sterilized by one of these three methods will be added to the basal mineral salts agar to give a final concentration of $1 \%$. For example, add $10 \mathrm{ml}$ of $10 \%$ solution to $100 \mathrm{ml}$ basal medium, or $100 \mathrm{ml}$ of a $10 \%$ solution to $1000 \mathrm{ml}$ basal medium.

B. Pridham and Gottlieb trace salts (only $1 \mathrm{ml}$ of this solution is used per liter of final medium)

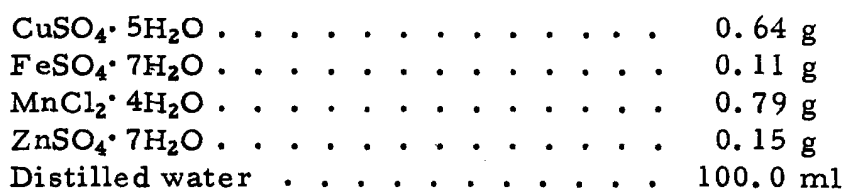

Store at $3-5^{\circ} \mathrm{C}$ until required for use. Bring to room temperature before using. Prepare fresh solution each month. Disregard any precipitate or scale (probably iron salts) that forms during storage. (Only $1 \mathrm{ml}$ of this solution will be used in the medium.)

C. Basal mineral salts agar (use analytical reagent grade

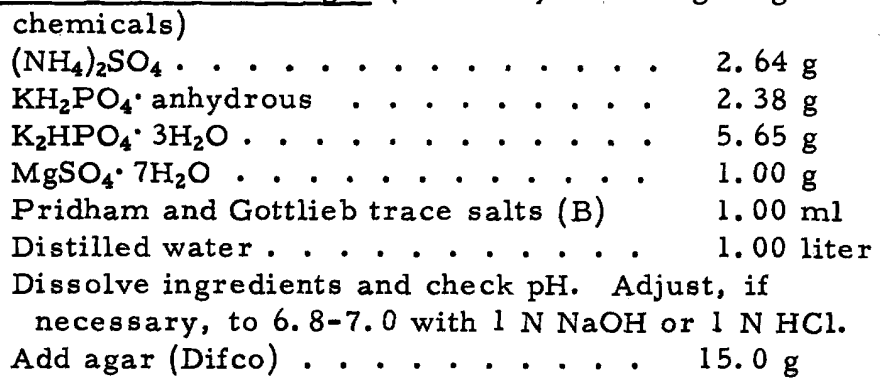

D. Complete medium

Sterilize basal agar medium (C); cool it to $60^{\circ} \mathrm{C}$ and add sterile carbon source (A) aseptically to give a concentration of approximately $1 \%$. Agitate the mixture and pour $25 \mathrm{ml}$ of medium per dish into $9 \mathrm{~cm}$ Petri dishes. Each organism will require 2 Petri dishes with no carbon (as a negative control) plus duplicate plates for each carbon source tested. (Page 335 ) 


\section{METHODS FOR INITIATING GROWTH AND PREPARING STOCK CULTURES FROM LYOPHILE PELLET}

1. Make a file scratch on ampoule at a location near upper part of looped cord (see Fig. I).

2. Immerse the unbroken ampoule into $70 \%$ ethyl alcohol.

3. Enclose the alcohol-moistened ampoule with a piece of sterile cotton or cotton and gauze; then snap or break it at the file scratch (Fig. 2).

4. Use sterile forceps or a sterile stiff wire hook to transfer the looped string and pellet to the labeled tube containing $5 \mathrm{ml}$ of sterile tryptone-yeast extract broth (Fig. 3). If a pellet fails to come out attached to the string, the cells or spores on the string will usually be adequate to start a good culture.

5. Shake the tube by hand until the pellet dissolves.

6. Incubate the tubes in a slanted position or on a mechanical shaker to give good aeration. Use of a shaker is the preferred method. Incubate at $25-28^{\circ} \mathrm{C}$ for $24-28$ hours (or until there is evidence of spore germination or growth).

7. Look for possible contaminants with the microscope. Also streak one loopful of the broth culture onto the agar surface of a Petri dish containing medium 2 (yeast extract-malt extract agar). This plate can be examined after a few days to confirm absence of contaminants.

8. Inoculate 6 or more test tube slants of medium 2 (yeast extract-malt extract agar) and of medium 3 (oatmeal agar) with 0.1-0.2 $\mathrm{ml}$ of the 24-48 hour growth. Streak material over entire surface of agar slant.

9. Incubate the slants at $25-28^{\circ} \mathrm{C}$ for 14 days to get mature stock cultures for use in preparation of inoculum (see section which follows). Then store stock slants in refrigerator $\left(6-10^{\circ} \mathrm{C}\right)$ until ready for use. Generally stock cultures for preparation of inoculum for characterization tests should be used within one month. 


\section{PREPARATION OF INOCULUM}

Use stock culture slants (prepared as described in the preceding section) for preparation of (A) general inoculum for all inoculations except carbon utilization test, and (B) a special washed inoculum for determining carbon utilization patterns.

\section{A. Preparation of general inoculum}

1. Prepare a supply of stoppered test tubes containing 3-5 $\mathrm{ml}$ of sterile distilled water.

2. Use a wire loop and standard aseptic technique to transfer spores, or mycelial growth, from a stock culture slant to one of the tubes of sterile distilled water.

a. If sporulation on the stock slant is good, transfer sufficient spore material to make a very turbid suspension in the distilled water. Normally most of the spore surface from a stock slant will be required. If necessary, use more than one slant to get a turbid suspension.

b. If spores are not formed, use the wire loop to transfer mycelial material to the tube of sterile distilled water. Triturate the mycelium in the distilled water with a sterile glass rod or the tip of a sterile pipette. Produce a very turbid suspension of mycelial fragments. Do not use a mycelial suspension if a good spore suspension (a) can be obtained.

3. This distilled water suspension of spores or mycelial fragments may be used immediately as general inoculum or may be held at room temperature 3-4 hours. Prepare fresh inoculum suspensions for tests performed on different days.

B. Preparation of washed inoculum

1. Prepare $5 \mathrm{ml}$ of turbid suspension of spores or mycelium in sterile water as described for general inoculum.

2. Transfer $4-5 \mathrm{ml}$ of this suspension to $50 \mathrm{ml}$ of medium 1 (tryptone-yeast extract broth) in a $250 \mathrm{ml} \mathrm{Erlenmeyer}$ flask (or $25 \mathrm{ml}$ in a $125 \mathrm{ml}$ flask). 


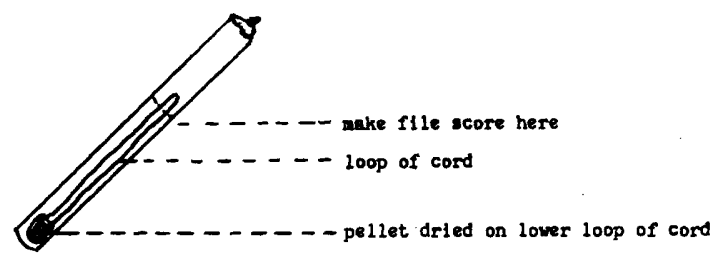

Figure 1: Sealed evacuated ampoule containing lyophile pellet and cord
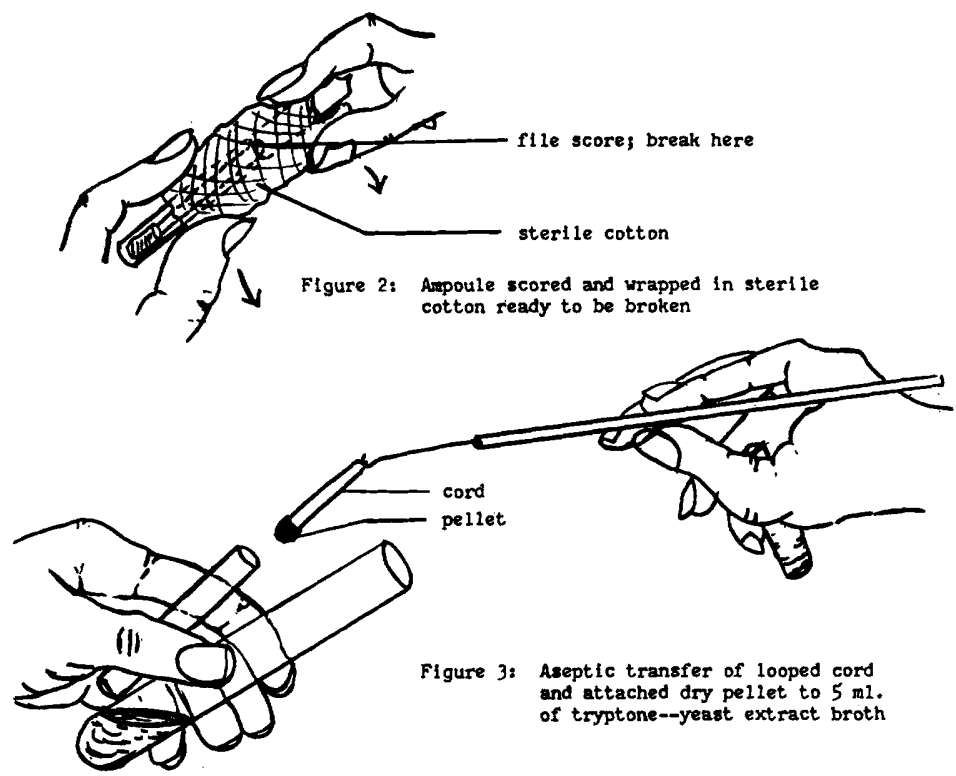
3. Incubate the flask for 48 hours at $25-28^{\circ} \mathrm{C}$. If possible the flask should be aerated on a mechanical shaker during the incubation.

4. Use vigorous agitation with sterile glass beads, a mechanical blender such as the Waring Blendor, or other appropriate means to break up the 48-hour growth.

5. Transfer $5-10 \mathrm{ml}$ of this fragmented broth culture into sterile centrifuge tubes equipped with sterile caps.

6. Centrifuge the suspension.

7. Decant the supernatant broth. Add sterile distilled water (or sterile $0.85 \% \mathrm{NaCl}$ ) to restore the original volume in the centrifuge tube. Mix and resuspend the washed sediment with a sterile rod or pipette.

8. Repeat steps 6 and 7. (Compare amount of sediment from different cultures. When amount of sediment is much less than normal amount, use proportionately less water for the final resuspension.)

9. Use the resuspended inoculum at once or within 3 hours to inoculate carbon utilization tests.

\section{PROCEDURES FOR CHARACTERIZATION OF CULTURES}

\section{MORPHOLOGICAL CHARACTERIZATIONS}

Accurate morphological characterization of the Actinomycetes producing catenulate spores is obviously dependent upon use of a culture medium giving good sporulation. Four media which gave good performance in this respect in previous cooperative studies are listed below as "standard" media. If these four media all fail to give good development of the sporulating aerial mycelium, then an additional medium promoting good spore formation should be used. ${ }^{5}$ If it is necessary to use an additional medium, also include a record of observations of the growth on the standard media. Spore chain and sporophore morphology should be determined by observation of a fully matured culture with good

5 Cooperators in the ISP will please communicate the formula of any additional medium used to Dr. Shirling, who will then forward the formula to the other two cooperating investigators studying the culture. 
spore formation. Do not use a culture in which degeneration through autolysis, hygroscopic properties, or extreme dehydration may have altered the morphology.

A. Culture media for morphological studies

1. The "standard" culture media for morphological studies for all cultures will be medium 2 (yeast extract-malt extract agar); medium 3 (oatmeal agar); medium 4 (inorganic salts - starch agar); and medium 5 (glycerol-asparagine agar).

2. Pour 7 plates of each medium using $25 \mathrm{ml}$ of medium in each $9 \mathrm{~cm}$ diameter Petri dish.

Media should be cooled to about $50^{\circ} \mathrm{C}$ and dispensed aseptically into sterile Petri dishes. Poured media should be held for a minimum of 24 hours at $25-28^{\circ} \mathrm{C}$ to promote moderate drying and to check sterility before inoculation.

B. Inoculation of plates for morphological studies

1. Use general inoculum prepared according to directions on page 322 .

2. Place about $0.05 \mathrm{ml}$ of the inoculum onto the agar surface near one edge of the Petri dish ( 1 drop from a $1 \mathrm{ml}$ serological pipette). This drop will serve as a "pool" of inoculum.

3. Use a flame-sterilized wire loop to make 5 equallyspaced streaks across the plate, dipping the loop into the pool of inoculum prior to each streak (see Fig. 4).

4. Make crosshatch streaks as shown in Fig. 5.

5. Inoculate a given culture onto at least 7 Petri dishes for each medium.

6. Incubate plates in the dark at $25-28^{\circ} \mathrm{C}$. For each culture observe two plates of each medium after 7 days, two at the end of 14 days, and two at the end of 21 days. One extra plate is inoculated in case of accident. 

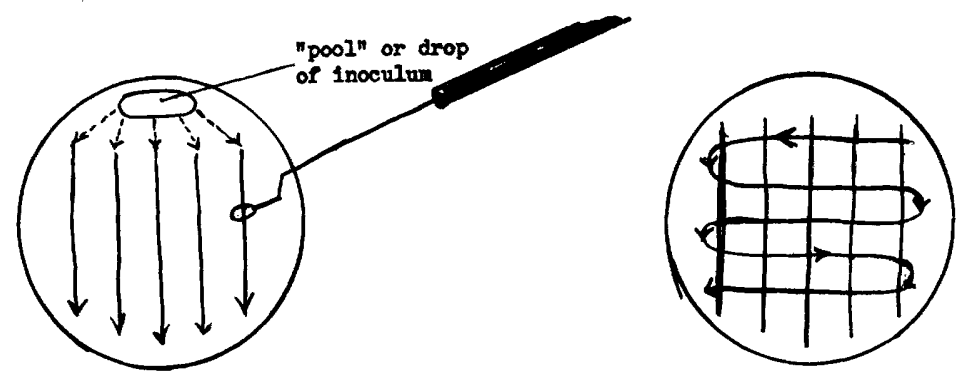

Figure L: Five initial streaks; loop dipped into inoculum for each streak

Figure 5: Cross streaks made without picking up additional inoculum

C. Determination of micromorphological characteristics of the spore-bearing hyphae

1. Determine the characteristics of the spore-bearing hyphae and spore chains by direct microscopic examination of the culture surface on opened dishes of the crosshatched cultures. Use a magnification adequate to establis h the presence (or absence) of chains of spores. This will usually be $100 x-700 x$. A minimum of 10 microscope fields at $100 x$ should be examined.

2. Determine the number of spores at the end of mature hyphae. State whether spores occur (a) singly, (b) in pairs, (c) in chains of $3-10$, or (d) in chains of more than 10 . If there is variation state the range of variation and then choose the most representative spore number $(a, b, c$, or $d)$ for the culture on a given medium. Make the observation on each medium which shows good sporulation.

3. The form of the spore chain and spore-bearing hyphae should be described only with mature cultures on which many well-defined spore chains can be seen. Describe sporulating cultures in terms of the morphological groups of Pridham et al. (1958), modified according to Baldacci (see Figs. 6-13). In some cases, particularly with cultures producing open loops and 
primitive spirals, more than one morphological type may be observed. On the basis of extensive observation of the culture surface, record all mature sporophore-spore chain types seen with an estimate of the percent of spore-bearing aerial hyphae falling into each category.

\section{SIMPLE}

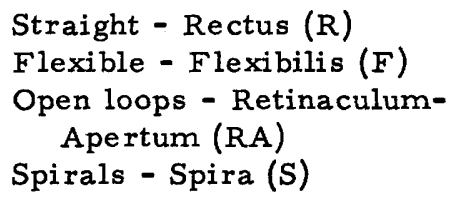

\section{VERTICILLATE}

Monoverticillus (MV)

Monoverticillus-

Spira (MV-S)

Biverticillus (BIV)

Biverticillus-Spira

$(\mathrm{BIV}-\mathrm{S})$

Undete rmined (U)

4. Photograph typical morphology of the sporulating hyphae, or make simple drawings.

5. Retinaculum-Apertum: Record the approximate diameter of characteristic open loops and primitive spirals of RA cultures.

6. Verticillate: (a) Record ave rage diameter of the main hyphae from which verticils originate. (b) Record whether or not verticils are evenly spaced along the. main hyphae.

D. Special morphological observations

It is also important to look for the following characteristics (usually identified with other actinomycete groups):

1. Presence of globular sporangia as in Actinoplanaceae

2. Presence of flagellated spores, as in Actinoplanes

3. Formation of conidia-like spores on the substrate hyphae

4. Tendency of the substrate mycelium to fragment

5. Occurrence of sclerotia. 


\section{BIMPLI}

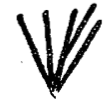

Figure 6. Rectus (R) or otralght

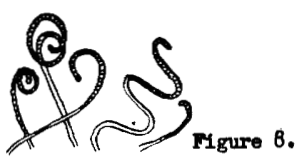

Retinaculuv-Apertuin (RA)

Open loops, hooks, or extended spirals of uide diameter.

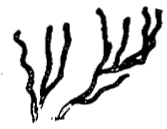

Figure 7. Mexibilis (F) or flexuous
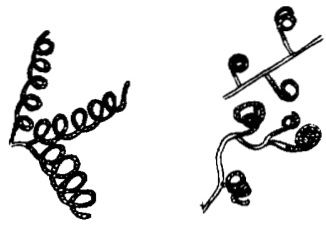

Figure 9. Splra (S)

Simple spirals (not on rerticils)

Spirals may be short and compact

or long, extended, or open

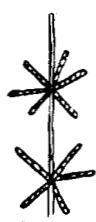

Figure 10. Yonoverticillus (MV)

Primary verticils or whorls

distributed on a long axds or branch; no spirals

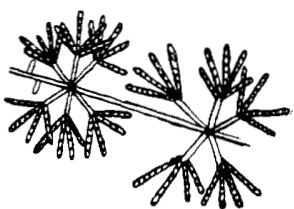

Figure 12. Biverticillus (BIV)

Compound verticils or whorls on

a long axis; no spirals

\section{VBRTICTHLATS}

rue verticillates have main axis of wider diameter than branching hyphae, and have uniform opacing betwoen verticile.

Pigure 11.

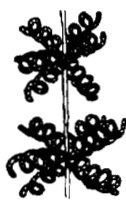

Monoverticillus-Spira (MV-S)

Primary verticils or whorls

distributed on a long axis;

elements of verticils spiralled

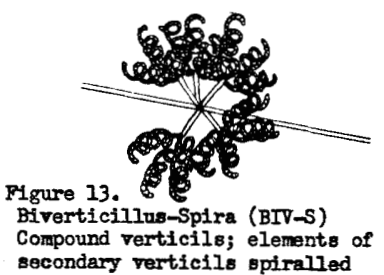

Figures 6-13. Reproduced from Pridham et al. (1958) with permission of authors and publisher. 
E. Spore morphology and surface

Laboratories having access to an electron microscope should include electron micrographs of the spore surface as one of the descriptive characterizations for each type culture. Electron micrographs should also show spore chains. Suggested method:

1. Use the same crosshatch Petri dish cultures prepared for observation under the light microscope.

2. Electron micros cope specimen grids coated with Formvar or collodion are gently pressed to the aerial surface of a culture with mature spores.

3. Spore chains which adhere to the coated surface of the grids are observed and photographed in the electron microscope without fixing or shadowing at a magnification of $8,000 x-10,000 x$.

4. Preserve the picture record to include with the report. In addition to the photographic record, spore silhouettes should be characterized as smooth, spiny, hairy, warty (see Fig. 14).

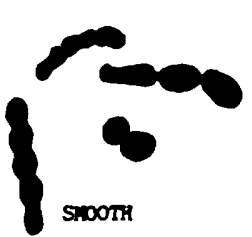

WRT

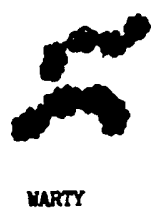

Figure 14.
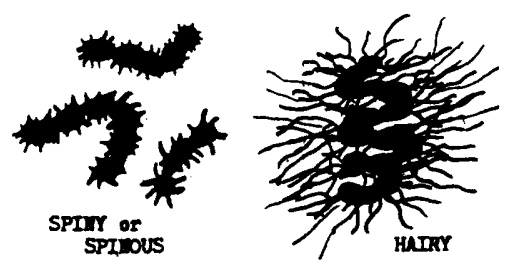

\section{COLOR DETERMINATIONS}

Color determinations should be made for (1) the mass color of mature, sporulating aerial surface growth, (2) for the color of the substrate mycelium as viewed from the reverse side, and (3) for diffusible soluble pigments other than melanins. The Tresner-Backus color series, adopted by participants in the 1962 Montreal Workshop (Küster, 1964; Tresner and Backus, 1963) is specified for spore mass color determinations, In this system, seven color series 
are delineated by color wheels made with tabs from the 3 rd or 4th edition of the Color Harmony Manual (Jacobson et al. 1948; Eckerstrom and Foss, 1958). 6 The Tresner-Backus color guide is not designed for determination of substrate mycelium colors or colors of soluble pigments. Although a color guide is not required for these colors, the substrate mycelium color may be identified in terms of a special guide $^{7}$ prepared for the I.S.P. by H. Prauser (1964) or in terms of the Bondartsev (1954) color scale.

A. Culture media for color determinations

Use the following media: Medium 2 (yeast extractmalt extract agar); medium 3 (oatmeal agar); medium 4 (inorganic salts - starch agar); and medium 5 (glycerolasparagine agar). The crosshatch plates that were prepared for morphological studies may be used for this purpose.

\section{B. Observations}

1. Observe plates at 7,14 and 21 days as prescribed for morphological studies. Color determinations should be recorded only for mature cultures.

2. Use north-window daylight on a bright day. If this is not posible, use a balanced and reproducible system of artificial light simulating north sky daylight.

C. Determination of aerial mass color

I. Observations should be limited to mature cultures with a heavy spore mass surface.

\footnotetext{
${ }^{6}$ A complete set of Tresner-Backus color guides has been provided to each participant in the I.S.P. Printed patterns for assembling the color wheels, together with reprints of the Tresner-Backus paper can be obtained without cost from Prof. E. B. Shirling, I.S. P., Ohio Wesleyan University, Delaware, Ohio 43015, U.S. A. Color Harmony Manual chips used in the guide may be purchased from Color Standards Department, Container Corporation of America, 38 South Dearborn St., Chicago, Illinois 60603, U.S.A. 7 Prepared for I.S. P. participants by H. Prauser from color tabs of Baumanns Farbtonkarte Atlas I. 
2. Determine the Tresner-Backus color series (Red, Yellow, Green, Blue, Violet, Gray or White) by comparing mature spore mass color on all appropriate media with the Tresner-Backus color wheels. Use only the mat (dull) surface of the color tabs. Most cultures will fall within the range delineated by one wheel. There are a few instances in which color tabs assigned to two different wheels are similar in color. If a culture is intermediate between these two tabs from different wheels, it may be difficult to choose one series as better than the other for describing the culture. In these rare cases classify the culture in both series.

3. Identify by number-letter code (printed on the tab), the one color tab which most nearly characterizes the spore-mass color. Also record the ISCC-NBS (U.S. Dept. of Commerce, 1955) name listed in the color wheel folder for the tab chosen to characterize the spore-mass color. If the color is intermediate between two tabs, designate both.

\section{Color of substrate mycelium (reverse color)}

The color of the substrate mycelium is determined by observing the reverse (under) side of mass growth on the various media. A method for removing most of the agar medium is described below. A simple guide for use in cutting off the agar is provided.

1. Place the cutting guide onto layers of filter paper or paper towel saturated with wet disinfectant solution (see Fig. 16). (Also provide a beaker of disinfectant for discarding work tools.)

2. Use a cork borer (or similar sharpened cylinder) with a diameter slightly less than the hole in the template to cut an agar plug from typical mature mycelial growth on a Petri dish culture (see Fig. 15). Determine color for (a) mature substrate mycelium and (b) the relatively young edges of the spreading growth.

3. Push the plug from the cylinder with a glass rod so that it turns over and drops inverted onto the cutting guide (Fig. 16). Push the inverted plug into the hole in the cutting guide. 
4. Slide a razor blade across the guide slicing off all agar medium which extends above the level of the surface (Fig. 17).

5. It is now possible to observe the reverse side of the culture plug remaining in the cutting guide. Very little agar will remain to interfere with color determination.

6. Assign the culture to one of the following color groups

(Szabó and Marton, 1964)

$$
\begin{aligned}
& \text { yellow-brown } \\
& \text { yellow-brown }+ \text { red (or orange) } \\
& \text { yellow-brown }+ \text { blue or violet } \\
& \text { yellow-brown }+ \text { green }
\end{aligned}
$$

7. In addition, if either Prauser or the Bondartsev color code or the complete Color Harmony Manual is available, identify the color with the nearest matching panel on one of these color guides.

8. Determine the response of color of substrate mycelium to $\mathrm{pH}$ change by adding a drop or more of $0.05 \mathrm{~N}$ $\mathrm{NaOH}$ and $0.05 \mathrm{~N} \mathrm{HCl}$ to the specimen prepared as described in steps 1-4 above. Make observations immediately and after 10 to 15 minutes.

E. Soluble colors other than melanoid pigmentation

If soluble colors other than brown or black are produced on any medium (or if brown is distinctly modified with red, yellow, green, blue, or violet), 1) record the medium; 2) record the color as the simple unmodified color name (red, orange, yellow, green, blue, violetuse no other color terminology); and 3) in every case of soluble color other than melanoid pigment, determine response of color to $\mathrm{pH}$ change by addition of a drop or more of $0.05 \mathrm{~N} \mathrm{NaOH}$ and $0.05 \mathrm{~N} \mathrm{HCl}$ to the colored agar. Record whether or not soluble color is affected by $\mathrm{pH}$ change. Make observations immediately and after 10 to 15 minutes. 


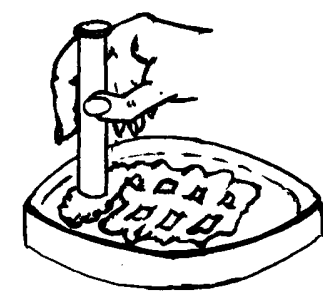

Figure 15: Cut agar plug from a broad mass of mature growth.

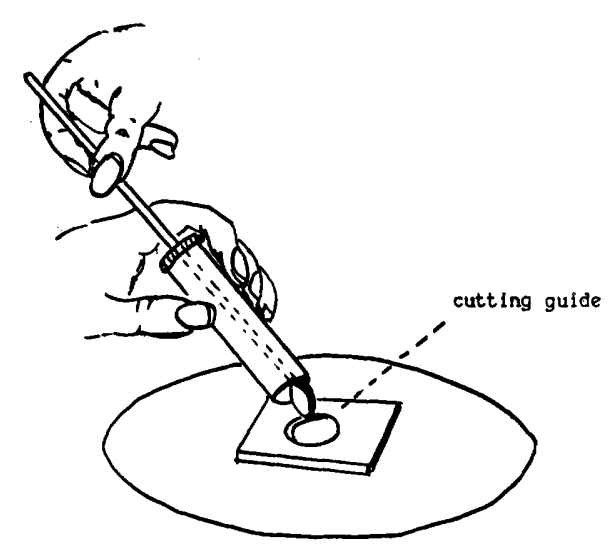

Figure 16: Push plug so that it drops inverted into the cutting guide.

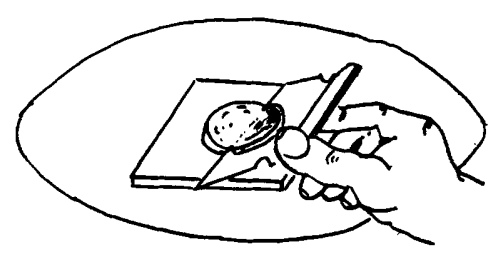

Figure 17: Use razor blade to cut off and discard all agar which extends above the surface of the cutting gulde. Observe the exposed reverse side of the pycellum which remains in the cutting guide. 


\section{PHYSIOLOGICAL CHARACTERISTICS}

\section{A. MELANIN PRODUCTION}

1. Culture media and inoculation for melanin production

Determine production of melanoid pigments on agar slants of medium 6 (peptone iron agar, Difco, supplemented with $0.1 \%$ yeast extract), and medium 7 (Shinobu's modification of Masumoto's tyrosine agar). Also observe other organic media, especially medium 1 (tryptone-yeast extract broth, used for obtaining growth from lyophile pellet).

Use agar slant cultures prepared as described under MATERIALS AND GENERAL METHODS as inoculum for media 6 and 7 . Cultures used as inoculum source should be less than 3 weeks old (except for cultures unusually slow in producing mature aerial growth). Use a heavy inoculum of spores and aerial mycelium picked up on a standard wire loop. Streak this inoculum up the surface of the agar slant. Inoculate each experimental culture onto 2 slants of medium 6 , and 2 slants of medium 7 .

\section{Observations and interpretations}

a. Observe melanoid pigments on medium 6 and medium 7 after 2 days and after 4 days. Compare inoculated tubes with uninoculated controls. Cultures forming a greenish brown to brown to black diffusible pigment or a distinct brown pigment modified by other color shall be recorded as positive ( + ). Absence of brown to black colors, or total absence of diffusible pigment, shall be recorded as negative (-) for melanoid pigment production.

b. Other organic media containing peptones or tyrosine, including medium 1 (tryptone-yeast extract broth) used for initial growth from the lyophile pellet, should be observed for production of melanoid pigments. The presence of pigments in these media should be included in the record. 


\section{B. CARBON UTILIZATION}

1. Basal medium and carbon sources

Detailed instructions for medium 9 (Pridham and

Gottlieb carbon utilization medium) including carbon source sterilization are given on pages 318-319.

After autoclaving the basal agar medium, cool it to $60^{\circ} \mathrm{C}$ and add sterile carbon source aseptically to give a concentration of approximately $1 \%$. Agitate the mixture and pour $25 \mathrm{ml}$ of medium per dish into $9 \mathrm{~cm}$ Petri dishes. Prepare duplicate plates of each carbon compound for each culture to be tested. Store medium in refrigerator.

Carbon sources and controls required for the test are repeated below:

No carbon source (negative control)

D-glucose (positive control)

L-arabinose

$\begin{array}{ll}\text { Sucrose } & \text { D-fructose } \\ \text { D-xylose } & \text { Rhamnose } \\ \text { I-inositol } & \text { Raffinose } \\ \text { D-mannitol } & \text { Cellulose }\end{array}$

2. Procedures for carbon utilization tests

a. Prepare a washed inoculum as described on pages 323-324.

b. Dry the uninoculated plates by leaving them at room temperature for 4 hours after they are freshly poured or after removing them from refrige rator storage.

c. Place approximately $0.05 \mathrm{ml}$ of washed inoculum (1 drop from a sterile $1 \mathrm{ml}$ serological pipette or dropping pipette) onto one edge of the agar surface. Streak the drop straight across the dish (see Fig. 18). Repeat with a second drop. Inoculate duplicate plates. Use only one culture per plate to avoid false positives due to cross feeding.

d. Observe plates at 10-16 days. Always compare growth on a given carbon source with the two controls; growth on basal medium alone, and growth on basal medium plus glucose. 
e. Record results as follows:

Strongly positive utilization $(++)$, when growth on tested carbon in basal medium is equal to or greater than growth on basal medium plus glucose.

Positive utilization $(+)$, when growth on tested carbon is significantly better than on basal medium without carbon, but somewhat less than on glucose.

Utilization doubtful $( \pm)$, when growth on tested carbon is only slightly better than on the basal medium without carbon and significantly less than with glucose.

Utilization negative (-), when growth is similar to or les s than growth on basal medium without carbon. (Always record utilization as negative if growth is not better than no-carbon control.)

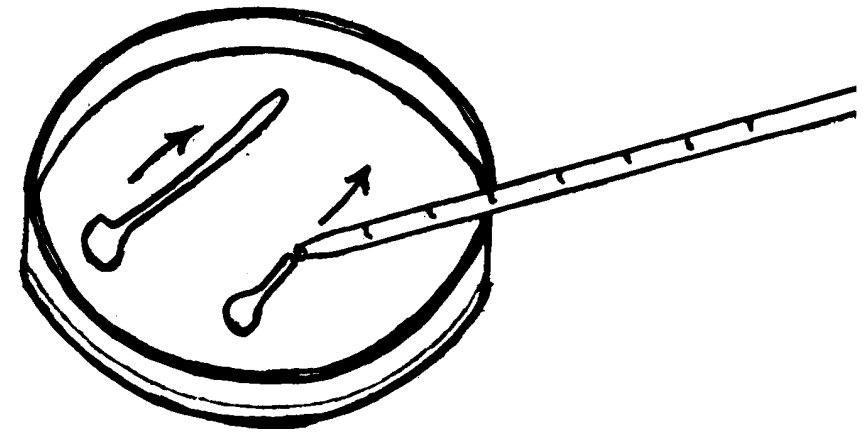

Figure 18.

\section{REFERENCES}

Bondartsev, A.S. 1954. Scale of colors. The Academy of Science, USSR.

Eckerstrom, R. and C.E. Foss. 1958. Color harmony manual, 4th ed. Container Corp. of America, Chicago.

Gottlieb, D. 1959. Agenda for Round Table evaluation of criteria for taxonomy. Intern. Bull. Bact. Nomen. and Taxon. 9:13-14.

- 1961. An evaluation of criteria and procedures used in the description and characterization of the streptomycetes. Appl. Microbiol. 9:55-65. 
- 1963. Recommendations for description of some Actinomycetales appearing in patent applications. Intern. Bull. Bact. Nomen. and Taxon. 13:159-160. Jacobson, E., W. C. Granville and C.E. Foss. 1948. Color harmony manual, 3 rd ed. Container Corp. of America, Chicago.

Judge, L. F. Jr., and M.J. Pelczar, Jr. 1955. The sterilization of carbohydrates with liquid ethylene oxide for microbiological fermentation tests. Appl. Microbiol. 3:292-295.

Krasil'nikov, N.A. 1960. Resolution of the "Conference on Taxonomy of Actinomycetes," held in Moscow, June 810, 1960. Intern. Bull. Bact. Nomen. and Taxon. I1 : 23-28.

Küster, E. 1959a. Outline of a comparative study of criteria used in characterization of the actinomycetes. Intern. Bull. Bact. Nomen. and Taxon. 9:98-104. - 1959b. Introductory remarks and welcome, "Round Table Conference on Streptomycetes" on occasion of the 7 th International Congress of Microbiology, Stockholm, August 4-5, 1958. Intern. Bull. Bact. Nomen. and Taxon. 9:57-61.

- 196̄. Results of a comparative study of criteria used in classification of the actinomycetes. Intern. Bull. Bact. Nomen. and Taxon. 11:91-98.

- 1964. Report on the activity of the Subcommittee on Taxonomy of the Actinomycetes, 1958-1962. Intern. Bull. Bact. Nomen. and Taxon. 14:1-3.

Prauser, H. 1964. Aptness and application of colour codes for exact description of colours of streptomycetes. Zeits chrift f. Allg. Mikrobiologie 4:95-98.

Pridham, T.G., P. Anderson, C. Foley, L. A. Lindenfelser, C. W. Hesseltine and R. G. Benedict. 1956-57. A selection of media for maintenance and taxonomic study of streptomycetes. Antibiotics Ann. 1956/57, pp. 947-953.

and D. Gottlieb. 1948. The utilization of carbon compounds by some Actinomycetales as an aid for species determination. Jour. Bacteriol. 56:107-114.

, C. W. Hesseltine and R.G. Benedict. 1958. A guide for the classification of streptomycetes according to selected groups. Placement of strains in morphological sections. Appl. Microbiol. 6:52-79.

and A.J. Lyons, Jr. 196 . Streptomyces albus (Rossi Doria) Waksman et Henrici: Taxonomic study of strains labeled Streptomyces albus. Jour. Bacteriol. 81:431-441. 
Shinobu, R. I958. Physiological and cultural study for the identification of soil actinomycete species. Mem. Osaka Univ. B. Nat. Sci. 7:1-76, (Modified)

Szabó, I. and M. Marton. 1964. Comments on the first results of the international cooperative work on criteria used in characterization of streptomycetes. Intern. Bull. Bact. Nomen. and Taxon. 14:17-38.

Tresner, H. D. and E.J. Backus. 1963. System of color wheels for streptomycete taxonomy. Appl. Microbiol. 11:335-338.

and F. Danga, 1958. Hydrogen sulfide production by Streptomyces as a criterion for species differentiation. Jour. Bacteriol. 76:239-244.

U.S. Department of Commerce. 1955. The ISCC-NBS method of designating colors and a dictionary of color names. National Bureau of Standards Circular 553, U.S. Gov't Printing Office, Washington 25, D. C.

\section{LIST OF PARTICIPANTS}

1. Shirling, Dr. E. B. (Coordinator) (Addressee for all I.S.P. correspondence). Dept. Botany and Bact., Ohio Wesleyan Univ. Delaware, Ohio, U.S.A.

2. Gottlieb, Dr. David (Coordinator)

Dept. Plant Pathology, Univ, of Illinois, Urbana, Illinois, U.S.A.

3. Anderson, Lucia (Sara Wold)

Parke, Davis and Co., Detroit, Michigan, U.S.A.

4. Baldacci, Prof. Elio

Ist. Patol. Vegetale, Univ. Milano, Via Celoria N. 2, Milano, Italy

5. Brinkmann, Dr. Rolf

Organic Chem. Inst., Univ. of Gottingen, Gottingen, Germany

6. Crook, Dr. Kenneth E., Jr. (Carol S. Cassidy)

Bristol Labs., Inc., Syracuse, New York, U.S. A.

7. Cross, Dr. T. (A. Maciver)

Dept. Biol. Sciences, Bradford, Inst. Tech.,

Bradford 7 / Yorkshire, England

8. devries, Dr. G. A.

Centraalbureau voor Schimmelcultures, Baarn, Netherlands

9. Dietz, Alma

Upjohn Co., Kalamazoo, Michigan, U.S.A. 
10. Falcão de Morais, Dr. J.O.

Inst. de Quimica da Úniv. do Recife, Recife, Pernambuco, Brazil.

11. Gause, Prof. Dr. G.F. (Preobrashenskaja, Kudrina, Maximova, Sveshnikova)

Acad. Med. Sciences of USSR, Inst. New Antibiotics, Moscow, USSR

12. Higgens, Mr. Calvin E.

Eli Lilly and Co., Indianapolis, Indiana, U.S.A.

13. Hirsch, Dr. Peter

Dept. Microbiol., Yale Univ., New Haven, Connecticut, U.S.A.

14. Hütter, Dr. Ralf

Inst. für Spez. Bot., Eidg. Tech. Hochschule,

Zürich 6, Switzerland

15. Johanides, Prof. Dr. Vera (T. Kos)

Zabod za mikrobiologiju, Zagreb, Pierottijeva, 6, Jugoslavija

16. Krasil'nikov, Prof. N.A.

Inst. Microbiol., Acad. Sciences, Moscow B-133, USSR

17. Kuznetsov, Dr. V.D.

USSR Res. Inst. for Antibiotics, Moscow, USSR

18. McClung, Dr. Norvel

Dept. Bact., Univ. Georgia, Athens, Ga., U.S.A.

19. Mach, Prof. Dr. F.

Inst. für Mikrobiologie, Greifswald, Ludwig-Jahn-Str. 15, Germany

20. Margalith, Dr. P.

Lab. of Microbiol., Is rael Inst. of Tech. Haifa, Is rael

21. Nakazawa, Dr. K.

Takeda Chem. Ind., Ltd., Juso-Higashiyodogawaku,

Osaka, Japan

22. Nishimura, Dr. Haruo (Mayama, Tawara)

Shionogi Res. Lab., Shionogi and Co., Ltd.,

Fukushima-ku, Osaka, Japan

23. Ohara, Dr. Y. (Nonomura)

Faculty of Engineering, Yamanashi Univ., Kofu, Japan

24. Okami, Dr. Yoshiro

Nat'l. Inst. of Health of Japan, Shinagawa, Tokyo,

Japan

25. Oliver, Mr. Thomas

Abbott Laboratories, N. Chicago, Illinois, U.S.A.

26. Prauser, Dipl. Biol. H.

Inst. Mikrobiol. Exp. Therapie, Beuthenbergstr. 11, Jena, Germany 
27. Pridham, Dr. Thomas

U.S. Borax Corporation, 412 Crescent Way, Anaheim, California, U.S. A.

28. Radziminska, Ina Hoffman-LaRoche, Nutley, New Jersey, U.S.A.

29. Řeháček, Dr. Zdenĕk (Alona Ričicová)

Czech. Acad. of Science, Inst. of Microbiol. ,

Prague 4, Budejovicka No. 1083, Czechoslovakia

30. Routien, Dr. John B. (Corinne Clevenger)

Charles Pfizer and Co., Inc., Groton, Conn., U.S. A.

31. Sanchez-Marroquin, D :. A. Miami 40, Mexico 18 / D. F., Mexico

32. Shewan, Dr. J.M. (T.G. Mitchell)

Torry Research Station, Aberdeen, Scotland

33. Spyvee, Mr. J. (J. Elliott)

Boots Pure Drug Co., Ltd., Antibiot. and Ferm.

Div., Nottingham, England

34. Srivistava, Dr. O.P.

Central Drug Res. Inst., Lucknow (U. P.), India

35. Szabó, Dr. I.

Magyar Tudományos Akadémia, Talajtani És

Agrokémiai Kutató Intézete, Budapest, Hungary

36. Tanaka, Dr. Nobuo

Inst. of Appl. Microbiol., Univ. of Tokyo, Bunkyo$\mathrm{ku}$, Tokyo, Japan

37. Thirumalachar, Dr. M.J.

Hindustani Antibiotics Res. Center, Pimpri, Near

Poona, India

38. Trejo, Dr. Wm. and Dr. Ralph Bennett

E. R. Squibb and Sons, New Brunswick, N. J., U.S.A.

39. Tresner, Dr. Homer

Lederle Labs., Pearl River, New York, U.S.A.

40. Tsyganov, Dr. V.A.

Res. Inst. of Antibiotics, Leningrad, L-20, USSR

41. Vernon, Dr. T.R.

Dept. Scientific and Ind. Res., Private Bag,

Auckland $\mathrm{Cl}$, New Zealand

42. Wallhäuser, Dr. Karl H.

Mikrobiolog. Unters, Farbwerke Hoechst AG,

Frankfurt a/M - Höchst, Germany

43. Williams, Dr. S. T.

Hartley, Botan. Labor., Univ. of Liverpool, Liverpool, England

44. Woźnicka, Dr. Wanda

Państwowy Zaklad Higieny, ul. Chocimska 24, Warsz awa 12, Poland 